\title{
The gut bacterial microbiota of sea turtles differs between geographically distinct populations
}

\author{
T. Franciscus Scheelings ${ }^{1, *}$, Robert J. Moore ${ }^{2}$, Thi Thu Hao Van ${ }^{2}$, Marcel Klaassen ${ }^{3}$, \\ Richard D. Reina ${ }^{1}$
}

\begin{abstract}
${ }^{1}$ School of Biological Sciences, Monash University, Wellington Rd, Clayton, Victoria 3800, Australia ${ }^{2}$ School of Science, RMIT University, Bundoora West Campus, Plenty Rd, Bundoora, Victoria 3083, Australia ${ }^{3}$ Centre for Integrative Ecology, Deakin University, Waurn Ponds, Victoria 3216, Australia
\end{abstract}

\begin{abstract}
The microbiota of metazoans can be influenced by a variety of factors including diet, environment and genetics. In this study we sampled multiple populations from 2 host species that do not overlap in distribution, in order to test whether their bacterial microbiotas are speciesspecific or more variable. Intestinal swabs were collected from loggerhead turtles originating from Florida, USA, and Queensland, Australia, as well as from flatback turtles from Crab Island, Queensland, and Port Hedland, Western Australia. We then manually extracted bacterial DNA and used 16S rRNA sequencing to explore bacterial microbial community composition and structure. Our investigation showed that the bacterial microbiota of sea turtles is heavily influenced by geography, with loggerhead turtles originating from the USA and Australia harbouring significantly different bacterial microbial populations in terms of composition. Similarly, we also found that flatback turtles from Crab Island had significantly less diverse microbiotas, with a predominance of the bacterial phylum Firmicutes, in comparison to their genetically similar counterparts from Port Hedland. Factors that may explain these observed differences between populations include host genetics, differences in foraging habitat quality and differences in migratory distance (and thus durations of inappetence) between foraging and breeding grounds. The mechanisms by which these factors may influence bacterial microbial composition of sea turtle gastrointestinal tracts warrants further investigation. The results of this study highlight the importance of interpreting microbiota data of wild animals in the context of geography.
\end{abstract}

KEY WORDS: Microbiota $\cdot$ Flatback turtle $\cdot$ Loggerhead turtle $\cdot$ Geography

\section{INTRODUCTION}

The composition of the gastrointestinal microbiota is determined by the same ecological principles that drive diversity and niche occupancy within macroecosystems. That is, colonist assemblages are established by founder populations, dispersal, diversification, local abundance, ecological drift, and habitat quality (Costello et al. 2012, Koskella et al. 2017). These are further influenced by individual bacterial traits such as dispersal efficiency and mutation rates,

*Corresponding author: fscheelings@hotmail.com as well as host genetics (Costello et al. 2012, Coyte et al. 2015). Thus, the final bacterial community of an individual is determined by a complex interplay of local and external factors, with microorganisms competing to establish stable populations within the gastrointestinal environment (Costello et al. 2012, Coyte et al. 2015).

In humans, diet strongly influences the composition of gut bacterial microbiota (Albenberg \& Wu 2014, David et al. 2014, Voreades et al. 2014). Transient fluctuations in community structure may

() The authors 2020. Open Access under Creative Commons by Attribution Licence. Use, distribution and reproduction are unrestricted. Authors and original publication must be credited. 
become evident in as little as $24 \mathrm{~h}$ after consumption of novel dietary items (David et al. 2014). Such plasticity may confer teleological advantages by permitting human dietary and lifestyle diversity (David et al. 2014), but it may also be a contributing factor in the development of disease (Albenberg \& Wu 2014). Genetics are also a strong driver of microbiota composition in humans, with potential implications for host metabolism (Spor et al. 2011, Goodrich et al. 2014).

As in humans, the gut microbiota of animals may be influenced by factors such as genetics (Zhao et al. 2013) and diet (Nelson et al. 2013, Frese et al. 2015, Henderson et al. 2015). Furthermore, disturbances in habitat quality appear to have species-specific effects on microbial populations of animals. Black howler monkeys Alouatta pigra inhabiting suboptimal environments consumed less diverse diets and had a corresponding decrease in gut microbial diversity. Additionally, genetic analysis of microbes isolated from these animals revealed a reduction in genes associated with butyrate production and hydrogen metabolism, which may have implications for host health, because the animals are unable to use environmental resources as efficiently as animals from pristine habitats (Amato et al. 2013). Conversely, a study involving multiple primate species demonstrated that habitat perturbation did not influence fecal microbiotas and that differences observed were explained by differences in digestive physiology and dietary preferences (McCord et al. 2014). However, in this same study, differences were noted between populations of the same species from different countries, suggesting that geography and social group membership influence microbial communities in some primates (McCord et al. 2014).

Despite the apparent malleability of the microbiota, investigations in mice have revealed that populations harbor a core microbial community, which is subject to host genetic control (Benson et al. 2010, Zhang et al. 2010). The relative abundances of taxa within this core microbiota collectively behave as a complex polygenic trait and they may exert their effects on other taxonomic groups and subsequently affect their ability to establish within the gastrointestinal tract (Benson et al. 2010). This multifaceted relationship between microbes and their hosts may be one of the key drivers of evolution and account for some of the enormous diversity we see in form and function of metazoans (Fraune \& Bosch 2010). However, in order to understand the importance of microbes in driving host evolution, investigations of a wider variety of host taxa are needed.
In comparison to other vertebrate classes, reptiles are grossly underrepresented in bacterial microbiota studies; however, in recent times, attention has started to focus on describing the bacterial community composition of this evolutionarily significant taxon (Hong et al. 2011, 2015, Keenan et al. 2013, McLaughlin et al. 2015, Yuan et al. 2015, Ren et al. 2016, Arizza et al. 2019, Holmes et al. 2019, Lin et al. 2019, Tang et al. 2019, Willson et al. 2019, Zhang et al. 2019, Fugate et al. 2020). Like other vertebrates, the bacterial microbiota of reptiles may be influenced by intrinsic and extrinsic factors such as host lineage (Ren et al. 2016), diet (Jiang et al. 2017, Holmes et al. 2019, Bloodgood et al. 2020, Montoya-Ciriaco et al. 2020), anorexia (Lin et al. 2019), food consumption (Costello et al. 2010), habitat (Littleford-Colquhoun et al. 2019), sex (Martin et al. 2010), climate change (Bestion et al. 2017), captivity (Kohl et al. 2017, García-De La Peña et al. 2019), exposure to chemicals (Indest et al. 2018), and gestation (Trevelline et al. 2019). In the largest investigation into sea turtle microbiotas conducted to date, microbial communities were strongly linked to sea turtle phylogeny, through a process of co-evolution between gut microbial inhabitants and the host (Scheelings et al. 2020a). While microbiota composition is strongly linked to health in humans (Shreiner et al. 2015), establishing these same relationships in sea turtles is difficult, with no correlation found between gut microbiota samples and a range of blood parameters in flatback turtles Natator depressus (Scheelings et al. 2020b). Exposure to glyphosate-based herbicides has been shown to reduce growth and survival of selected gut bacterial isolates from green turtles Chelonia mydas, with potential negative implications for gut physiology and health (Kittle et al. 2018). Also, in green turtles, an ontogenetic shift in microbial composition has been observed when animals transition from a pelagic lifestyle as juveniles to a neritic habitat as subadults (Price et al. 2017, Campos et al. 2018). Differences in microbiota composition of juvenile green turtles have been shown to exist between animals originating from different localities (Ahasan et al. 2017, Price et al. 2017, Campos et al. 2018); however, these investigations were conducted separately rather than as a single study aiming to determine the effects of geography on bacterial community structure. Similarly, the bacterial microbiota of loggerhead turtles Caretta caretta, seems to vary markedly between studies (Abdelrhman et al. 2016, Arizza et al. 2019, Biagi et al. 2019, Scheelings et al. 2020a), despite the fact that most of the animals from these investigations originated from the same 
genetic stock in the Mediterranean Sea (Pritchard 1997, Duchene et al. 2012). Understanding the microbiota, and how it has shaped vertebrate life, is particularly important for less-studied species, such as the Reptilia, in order to gain a complete understanding of the evolutionary processes driving host-microbe relationships. To address this deficit in the reptile literature, we chose to explore the potential associations that exist between geography and bacterial gut microbiota in sea turtles.

There are 7 extant species of sea turtles, which may occupy a diverse array of ecological niches and employ a variety of foraging strategies (Bowen \& Karl 2007). The global phylogeography of sea turtles is markedly influenced by habitat preference and thermal tolerance (Bowen \& Karl 2007). For example, the more cold-adapted leatherback turtles Dermochelys coriacea show the lowest geographic structuring as their large size and pelagic lifestyle permits them to traverse through the boreal waters that act as a barrier to other warm-water adapted turtles (Bowen \& Karl 2007). Conversely, tropical species, such as green turtles, hawksbill Eretmochelys imbricata turtles, and ridley turtles (Lepidochelys olivacea and $L$. kempii) have ancient separations between Atlantic and Indo-Pacific populations caused by the closure of the Isthmus of Panama around 3.5 million years ago (Bowen \& Karl 2007). Within sea turtle species, there may be genetically distinct populations living within the same broad geographic regions, as well as genetically distinct populations living in very separate geographic regions. Alternatively, there may also be limited genetic variation of some species living in separate populations but within the same broad geographic area. For example, loggerhead turtles that nest on the east coast of Australia are genetically distinct from those that nest on the west coast of Australia (Limpus 2008b), and both of these populations are distinct from animals that nest in Florida, USA (Bowen \& Karl 2007). In contrast, there is very little genetic diversity among flatback turtles, despite there being 4 distinct nesting populations within Australia, with no inter-population breeding (Limpus 2008a). These phylogeographic traits make sea turtles interesting subjects to study in the context of bacterial microbiotas and to explore the influence of genetic and environmental factors on microbial community structures. The aims of this investigation were to explore whether variations in microbiota can be seen between different groups of the same species of sea turtles and to identify possible explanations for any observed disparities. To do this, we investigated how microbiotas differed among populations of log- gerhead turtles in Australia and the USA, as well as between different populations of flatback turtles within Australia.

\section{MATERIALS AND METHODS}

\subsection{Study populations}

Nesting adult flatback turtles of unknown age were sampled from Crab Island $(n=20)$, Queensland $\left(10.972^{\circ} \mathrm{S}, 142.106^{\circ} \mathrm{E}\right)$, in September 2016, and from Port Hedland $(\mathrm{n}=17)$, Western Australia $\left(20.3107^{\circ} \mathrm{S}\right.$, $118.5878^{\circ} \mathrm{E}$ ), in November 2016. Animals from these 2 areas are considered to be from genetically separate populations with little gene flow between them (Limpus 2008a). Loggerhead turtles were sampled from Mon Repos $(\mathrm{n}=20)$, Queensland $\left(24.8059^{\circ} \mathrm{S}\right.$, $\left.152.4416^{\circ} \mathrm{E}\right)$, in January 2017, and from Juno Beach $(\mathrm{n}=20)$, Florida, USA $\left(26.5224^{\circ} \mathrm{N}, 80.315^{\circ} \mathrm{E}\right)$, in May 2018. These 2 populations of loggerhead turtles represent distinct genetic stocks (Duchene et al. 2012).

\subsection{Sample collection}

If turtles were nesting, we waited until they had finished laying and were returning to the ocean. We then flipped them into dorsal recumbency, and an equine uterine swab (Minitube) was inserted into the cloaca so that it entered the distal colon. These swabs are approximately $90 \mathrm{~cm}$ in length, and each swab was inserted to a depth of at least $60 \mathrm{~cm}$. Based on previous research conducted by our research group in which endoscopy was used to visualise the cloacal structures of sea turtles (Rafferty et al. 2013), we are confident that inserting the swabs to this depth permitted sampling of the distal colon and not the cloaca. These swabs were housed in a sterile sheath, the entire apparatus was inserted into the cloaca, and the swab tip was extruded when correct placement of the sheath had been achieved. The swab tip was then retracted back into the sheath prior to extraction to ensure that it had no contact with the external environment or an internal environment other than the distal colon, then the turtles were returned to ventral recumbency and permitted to return to the ocean. The tip of the swab was removed using a sterile wire cutter, placed into a sterile Eppendorf tube and sealed. Total sample collection time was approximately $10 \mathrm{~min}$. Negative control swabs were not collected as we were confident in our col- 
lection technique eliminating environmental contamination. The Eppendorf tube containing the swab was immediately placed into a portable cool box filled with ice, and once back at the field station they were frozen at $-20^{\circ} \mathrm{C}$ for approximately 3-4 d. Swabs were transported back to the laboratory using dry ice $\left(-78.5^{\circ} \mathrm{C}\right)$, where they were stored at $-80^{\circ} \mathrm{C}$ until extraction could take place approximately $1 \mathrm{wk}$ later.

\subsection{DNA extraction}

DNA was extracted manually using the phenolchloroform method (Green et al. 2012). In each Eppendorf tube, $500 \mu \mathrm{l}$ of extraction buffer consisting of $20 \mathrm{mM}$ ethylenediaminetetraacetic acid (EDTA), $0.1 \mathrm{M}$ Tris, 1\% cetrimonium bromide (CTAB), $56 \mathrm{mM} \mathrm{NaCl}, \mathrm{pH} 8$ was added so that swabs were completely covered. We then added $20 \mathrm{\mu l}$ of Proteinase K (Qiagen Proteinase K $(10 \mathrm{ml})$ $10 \mathrm{ml}$ (>600 mAU ml-1 solution)) to each vial, along with $60 \mu \mathrm{l}$ of $10 \%$ sodium dodecyl sulphate (SDS). The mixture was then incubated at $55^{\circ} \mathrm{C}$ overnight. The next day, $50 \mu \mathrm{l}$ of $5 \mathrm{M} \mathrm{NaCl}$ and $500 \mu \mathrm{l}$ of phenol was added, and the Eppendorf tubes were shaken until an emulsion was formed. Eppendorf tubes were then incubated at room temperature for $10 \mathrm{~min}$, with intermittent mixing. The Eppendorf tubes were then centrifuged (Microcentrifuge Fresco 21, Thermo Fisher) at $10000 \mathrm{rpm}(9638 \times g)$ for $10 \mathrm{~min}$ and the supernatant removed and added to a new Eppendorf tube containing $250 \mu \mathrm{l}$ phenol and $250 \mu \mathrm{l}$ chlorophorm: isoamyl-alcohol (24:1). The tubes were again centrifuged (Microcentrifuge Fresco 21, Thermo Fisher) at $10000 \mathrm{rpm}(9638 \times g)$ for $10 \mathrm{~min}$ and the resultant supernatant added to a new Eppendorf tube containing $500 \mu \mathrm{l}$ of chlorophorm: isoamyl-alcohol. Once again, the Eppendorf tubes were centrifuged (Microcentrifuge Fresco 21, Thermo Fisher) at $10000 \mathrm{rpm}(9638 \times \mathrm{g})$ for $10 \mathrm{~min}$. The supernatant was then added to a new Eppendorf tube containing $3 \mathrm{M}$ sodium acetate at a volume equal to $10 \%$ of the extraction solution. We then added $1 \mathrm{ml}$ of ice-cold $99 \%$ ethanol to each Eppendorf tube, which was then placed into a freezer at $-20^{\circ} \mathrm{C}$ for $1 \mathrm{~h}$. The Eppendorf tubes were then centrifuged (Microcentrifuge Fresco 21, Thermo Fisher) at $4^{\circ} \mathrm{C}$ at $12000 \mathrm{rpm}(13878 \times \mathrm{g})$ for $10 \mathrm{~min}$. The fluid in the Eppendorf tube was then removed with a glass pipette, and $1 \mathrm{ml}$ of ice-cold $70 \%$ alcohol was added. The Eppendorf tubes were centrifuged (Microcentrifuge Fresco 21, Thermo
Fisher) a final time at $4^{\circ} \mathrm{C}$ at $12000 \mathrm{rpm}(13878 \times g)$ for $5 \mathrm{~min}$. After centrifugation the alcohol was removed and the lids left off the Eppendorf tubes to allow the DNA pellet to dry. Once dried, $25 \mu \mathrm{l}$ of 1 $\times$ Tris-EDTA (TE) was added to each Eppendorf tube, and the extracted DNA was stored at $-20^{\circ} \mathrm{C}$ until amplicon sequencing could take place.

\subsection{S rRNA gene amplicon sequencing}

The V3-V4 region of 16S rRNA genes were amplified with forward primer 5' ACT CCT ACG GGA GGC AGC AG 3' and reverse primer 5' GGA CTA CHV GGG TWT CTA AT 3' using Q5 high fidelity polymerase (New England Biolabs) with the barcoding strategy of Fadrosh et al. (2014). Sequencing was performed on an Illumina MiSeq system $(2 \times 300 \mathrm{bp})$ on all samples simultaneously, and negative controls were included in the sequence run.

\subsection{Data processing}

Sequence data was analysed using QIIME version 1.9.1 (Caporaso et al. 2010) using default parameters and a Phred quality threshold of $>20$. The UCLUST algorithm (Edgar 2010) was used to pick operational taxonomic units (OTUs) at $97 \%$ sequence identity, and a Biome table was produced. Potentially chimeric sequences were identified using Pintail (Ashelford et al. 2005). BLAST was used to assign taxonomy against the Greengenes database (DeSantis et al. 2006) and QIIME version 1.9.1 defaults. Additional assignment of taxonomy was performed using a command line version of BLASTN (Altschul et al. 1997) against the NCBI 16S Microbial database.

\subsection{Statistics and data analysis}

Samples were rarefied to a minimum sequencing depth of 3000 reads. Initial exploration of the Biome table data was performed using the online Calypso software (http://cgenome.net/wiki/index.php/ Calypso) (Zakrzewski et al. 2017). Data was further analysed with R, utilising package 'phyloseq'. Alpha diversity was explored using observed OTUs, Shannon index and Chao1 estimates. Alpha diversity indices were tested for normality using the ShapiroWilks test and then parametric and non-parametric methods were adopted to test for significant differ- 
ences between groups. Shannon diversity in loggerheads $(W=0.92, \mathrm{p}=0.05)$ was the only normally distributed metric, and so comparisons between populations were made using ANOVA. All other measures were non-normally distributed: observed OTUs (loggerhead: $W=0.85, \mathrm{p}<0.01$; flatback: $W=0.88$, $\mathrm{p}<0.01$ ), Shannon diversity (flatbacks: $W=0.84, \mathrm{p}<$ 0.01), and Chao1 (loggerhead: $W=0.88, \mathrm{p}<0.01$; flatback: $W=0.87, \mathrm{p}<0.01$ ), and comparisons were made using the Kruskal-Wallis test. Beta diversity was investigated using principle coordinate analysis (PCoA) (Bray-Curtis) and Adonis tests. Linear discriminant analysis (LDA) effect size (LEfSe) was performed to determine if differential abundances of OTUs were attributable to location of capture with a size effect cut-off of 3.0 on the logarithmic LDA score used. For all statistical analyses significance was accepted if $\mathrm{p}<0.05$.

\section{RESULTS}

\subsection{Loggerhead turtles}

After rarefaction, we were able to include samples from 6 of the loggerheads from Juno Beach and 18 of the loggerhead turtles from Mon Repos (Table S1 in the Supplement; www.int-res.com/articles/suppl/ n042p095_supp.xlsx). In Juno Beach loggerheads we identified 201 OTUs, while from Mon Repos loggerheads we identified 272 OTUs. For both populations, the predominate phylum was Proteobacteria, with differential abundance in the 2 populations being observed for other phyla identified (Fig. 1a, Table S1). In animals from Mon Repos, the next most commonly isolated phyla were Spirochaetes, Bacteroides and Actinobacteria, while in Juno Beach animals Actinobacteria, Bacteroides and Firmicutes were the next most populous phyla (Fig. 1a). Alpha diversity differed significantly among loggerheads from the 2 different populations for all metrics: observed OTUs $\left(\chi^{2}=18.031, \mathrm{df}=1, \mathrm{p}<0.01\right)$, Shannon $\left(\mathrm{df}=1, \mathrm{SS}_{\mathrm{T}}=\right.$ 36.91, $\left.\mathrm{MS}_{\mathrm{T}}=36.91, F=54.98, \mathrm{p}<0.01\right)$, and Chao1 $\left(\chi^{2}=14.86, \mathrm{df}=1, \mathrm{p}<0.01\right)$ (Fig. 2a). Beta diversity, as assessed by PCoA, showed that the 2 populations clustered separately and distinctly from each other (Fig. 3). These observations were significantly different $\left(\mathrm{df}=1, \mathrm{SS}_{\mathrm{T}}=0.82, \mathrm{MS}_{\mathrm{T}}=0.82, F=2.6, \mathrm{R}^{2}=0.1\right.$, $\mathrm{p}=0.03)$. Overall, $37(29.6 \%)$ of the OTUs were shared between the 2 populations (Table S2). Sixtyone $(48.8 \%)$, OTUs were unique to animals from Mon Repos, in comparison to 27 (21.6\%) unique OTUs from animals from Juno Beach (Table S2). Lin- ear discriminant analysis revealed 27 OTUs to be responsible for explaining the variance seen between the different populations, with 20 of these being found in Mon Repos loggerheads and 7 being found in Juno Beach loggerheads (Fig. 4a, Table S3). Some of the most significant OTUs explaining variation for Mon Repos animals included Helicobacter helicobactermustelae_327563 and Vibrio sp._452638 (Fig. 4a), while for Juno Beach turtles the major OTUs responsible for explaining variation included Stenoxybacter sp._751919 and Pasteurellaceae_142268 (Fig. 4a).

\subsection{Flatback turtles}

After rarefaction, we were able to include samples from 19 of the flatbacks from Crab Island and from 10 of the flatbacks from Port Hedland (Table S4). In Crab Island flatbacks we identified 160 OTUs while in Port Hedland flatbacks we identified 241 OTUs. Firmicutes was the predominant phyla in animals from Crab Island, while Proteobacteria was the most commonly isolated phyla in Port Hedland turtles, followed by Actinobacteria, Bacteroidetes and Firmicutes (Fig. 1b, Table S4). Alpha diversity differed markedly among flatback turtle groups from the 2 different populations with significance noted for all metrics: observed OTUs $\left(\chi^{2}=18.031\right.$, $\left.\mathrm{df}=1, \mathrm{p}<0.01\right)$, Shannon diversity $\left(\chi^{2}=17.053, \mathrm{df}=1, \mathrm{p}<0.01\right)$, and Chao1 $\left(\chi^{2}=14.85, \mathrm{df}=1, \mathrm{p}<0.01\right.$ ) (Fig. 2b). Principal coordinate analysis of microbiota composition indicated that animals from Port Hedland and Crab Island had distinct and significant differences $(\mathrm{df}=1$, $\mathrm{SS}_{\mathrm{T}}=2.84, \mathrm{MS}_{\mathrm{T}}=2.84, F=10.175, \mathrm{R}^{2}=0.27, \mathrm{p}=$ 0.001 ) in their clustering patterns (Fig. 3b). Overall, $28(29.8 \%)$ OTUs were shared between the 2 populations (Table S5). Sixty-one (64.9\%), OTUs were unique to animals from Port Hedland, in comparison to $5(5.3 \%)$ unique OTUs from animals from Crab Island (Table S5). Linear discriminant analysis revealed 76 OTUs to be responsible for explaining the variance seen between the different populations, with 69 of these being found in Port Hedland turtles, and 7 being found in Crab Island turtles (Fig. 4b, Table S6). Some of the most significant OTUs explaining variation for Crab Island animals included Bacillus sp._161559, Bacillus sp._535651, Bacillis sp._161559, Bacillus sp._535651, and Bacillus endophyticus sp._410037 (Fig. 4b). For Port Hedland turtles the major OTUs responsible for explaining variation included Actinobacteria_108564, SUP05_ 285720, and Campylobacter campylobactercurvus 607889 (Fig. 4b). 


\section{a Loggerheads}
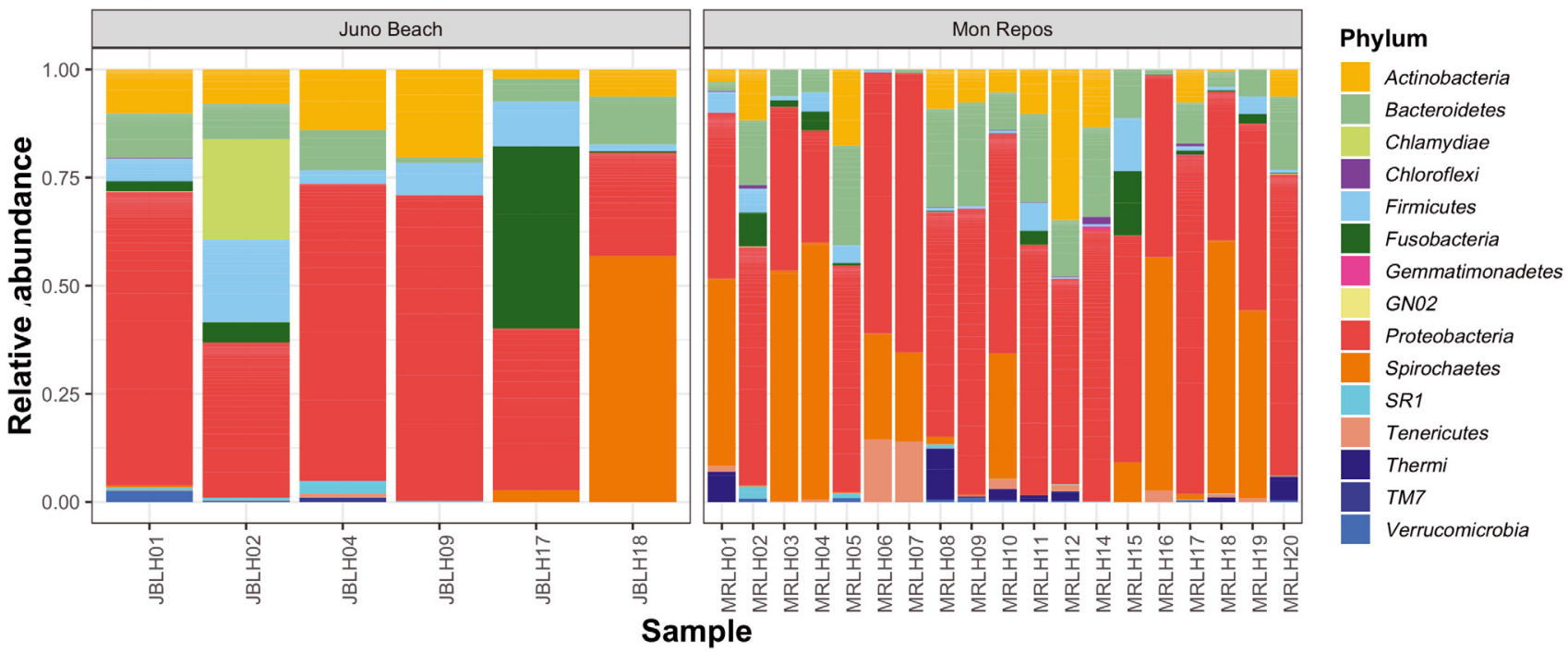

\section{b Flatbacks}
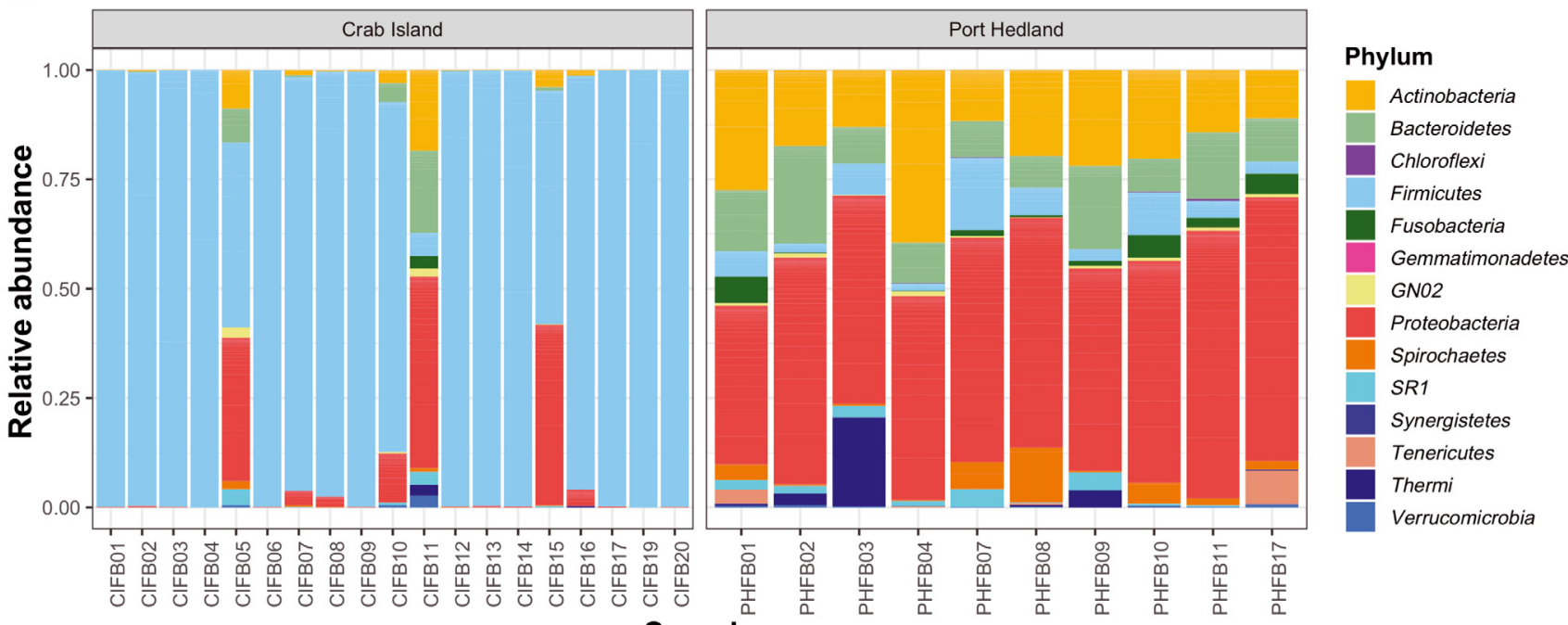

Fig. 1. Relative abundance of bacterial phyla identified in each sample. (a) Loggerhead sea turtles from Mon Repos, Queensland, Australia, and from Juno Beach (Juno Beach), Florida, USA. (b) Flatback sea turtles from Crab Island (Crab Island), Queensland, Australia, and from Port Hedland (Port Hedland), Western Australia, Australia

\section{DISCUSSION}

Sea turtles are cosmopolitan species with a worldwide distribution, are unusual among vertebrates in that they occupy a wide variety of ecological niches throughout their lives, and as adults they typically undergo long and physiologically arduous journeys for reproductive purposes. The phylogenetic history of sea turtles is well described on both a species level and between populations of the same species (Pritchard 1997, Duchene et al. 2012). Understanding the role that the microbiota has played in driving sea turtle phylogeny and physiology is the next important step in unravelling the complexities of their evolutionary history. Although a number of investigations exist which explore the microbiota of sea turtles (Abdelrhman et al. 2016, Ahasan et al. 2017, 2018, Price et al. 2017, Campos et al. 2018, Kittle et al. 2018, Arizza et al. 2019, Biagi et al. 2019), making meaningful comparisons between these studies and ours is challenging. Microbiome studies are complicated by differences in methods, differences in species sampled, and the nutritional status of sampled animals, which differed between these studies and 
a Loggerheads

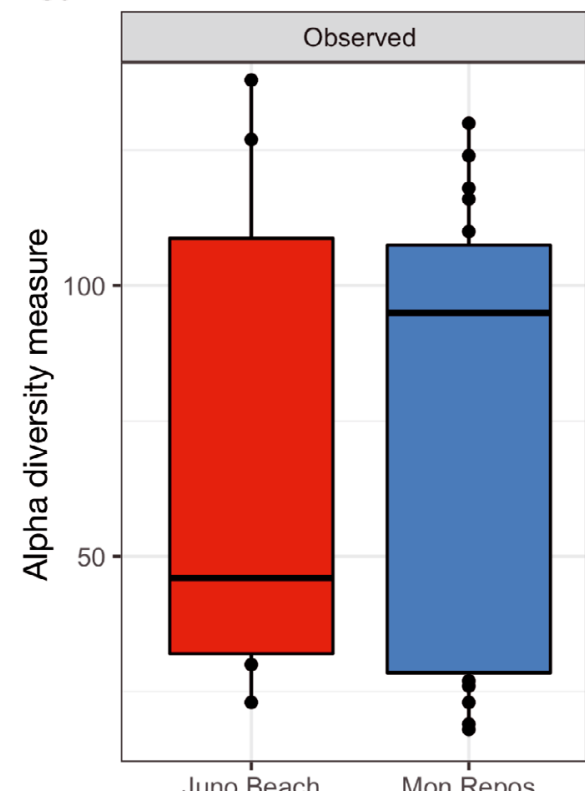

Juno Beach

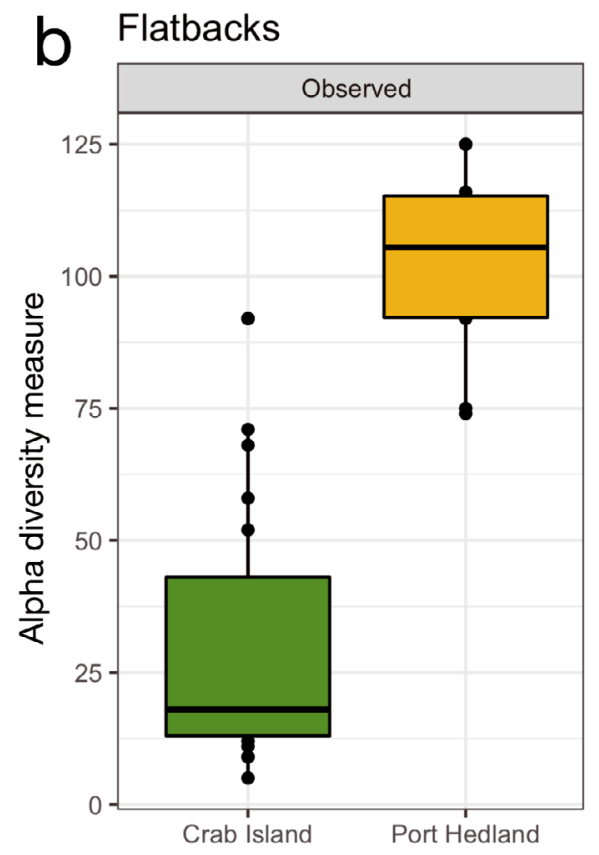

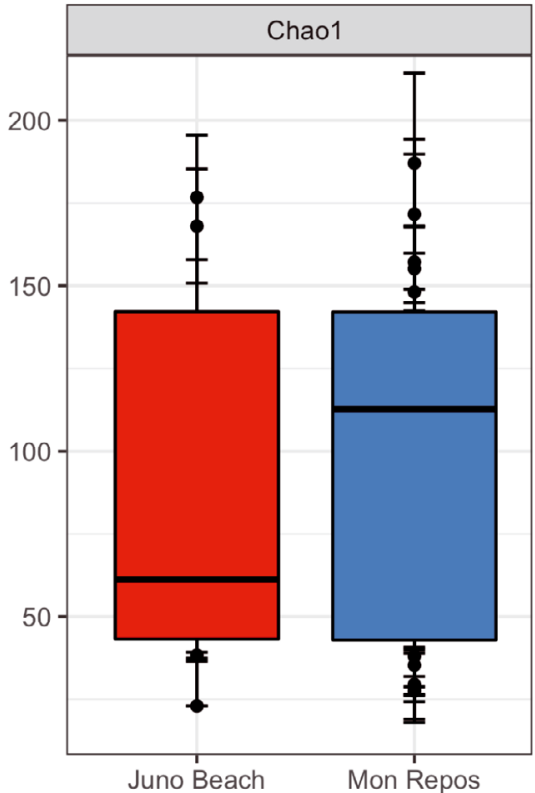

Location

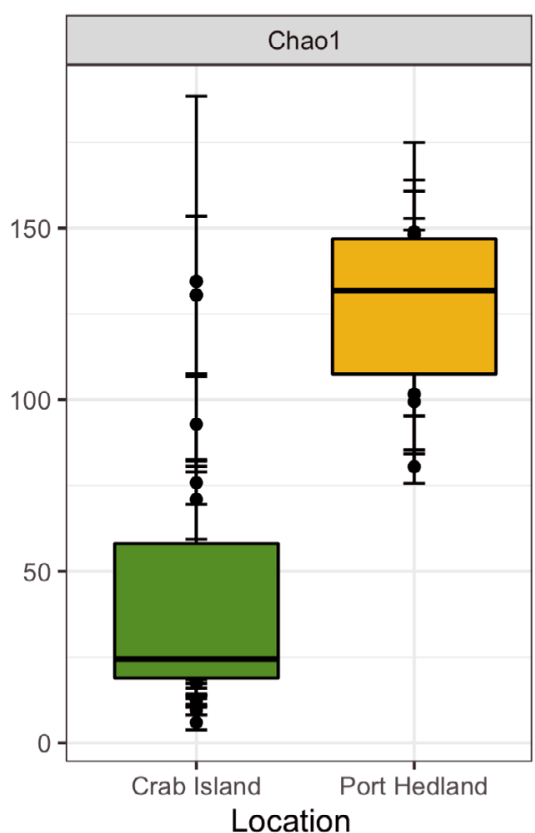

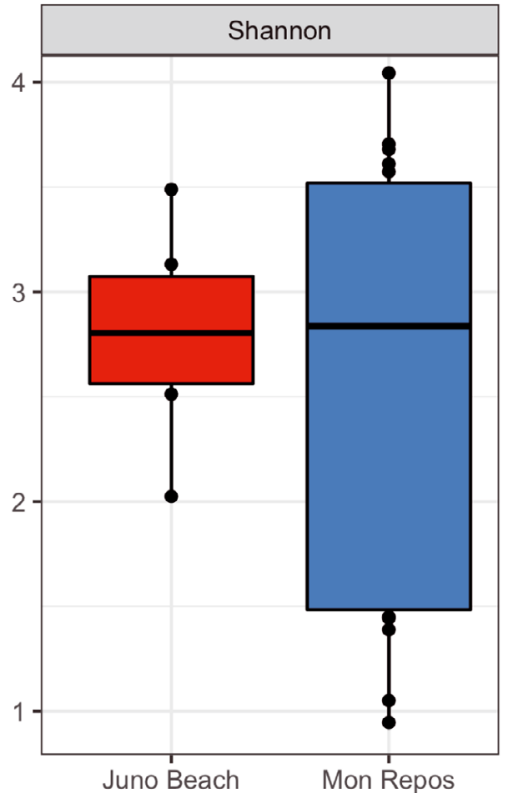

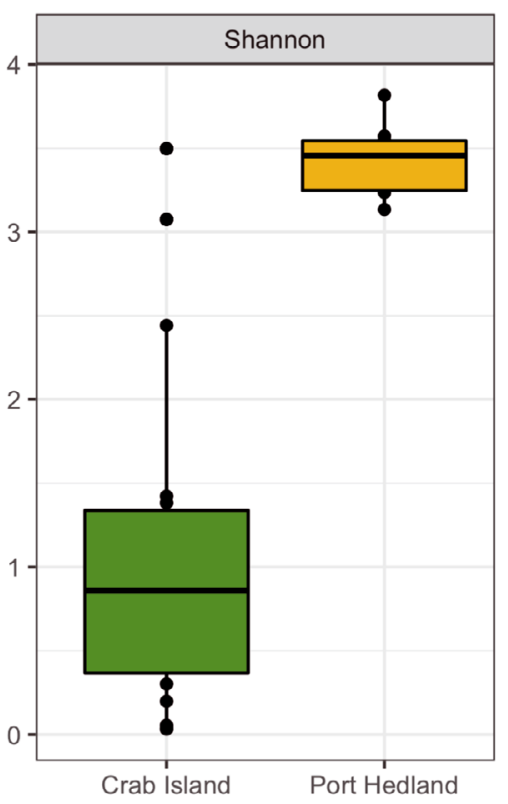

Fig. 2. Alpha diversity estimates for loggerhead and flatback sea turtles. Individual points and whiskers represent the richness estimate and the theoretical SE range associated with that estimate, respectively. Within each panel, the samples are organized into location of capture, and a boxplot is overlaid for the 2 groups (thick horizontal lines = median). (a) Loggerhead turtles showed differences in alpha diversity for all metrics: observed $(p<0.01)$, Chao1 $(p<0.01)$ and Shannon diversity ( $<<0.01)$ between the 2 populations. (b) Flatback turtles showed differences in alpha diversity for all metrics: observed ( $p<0.01)$, Chao1 $(\mathrm{p}<0.01)$ and Shannon diversity $(\mathrm{p}<0.01)$ between the 2 populations

the data we report here. Further, we sampled nesting turtles, which are physiologically distinct from sick/ injured or foraging turtles. Thus, because our goal was to interpret comparisons between microbiota composition subpopulations, we must turn to similar research on other taxa.

Our analysis of the bacterial microbiota of wild nesting sea turtles indicates that microbial communi- 


\section{a Loggerheads}

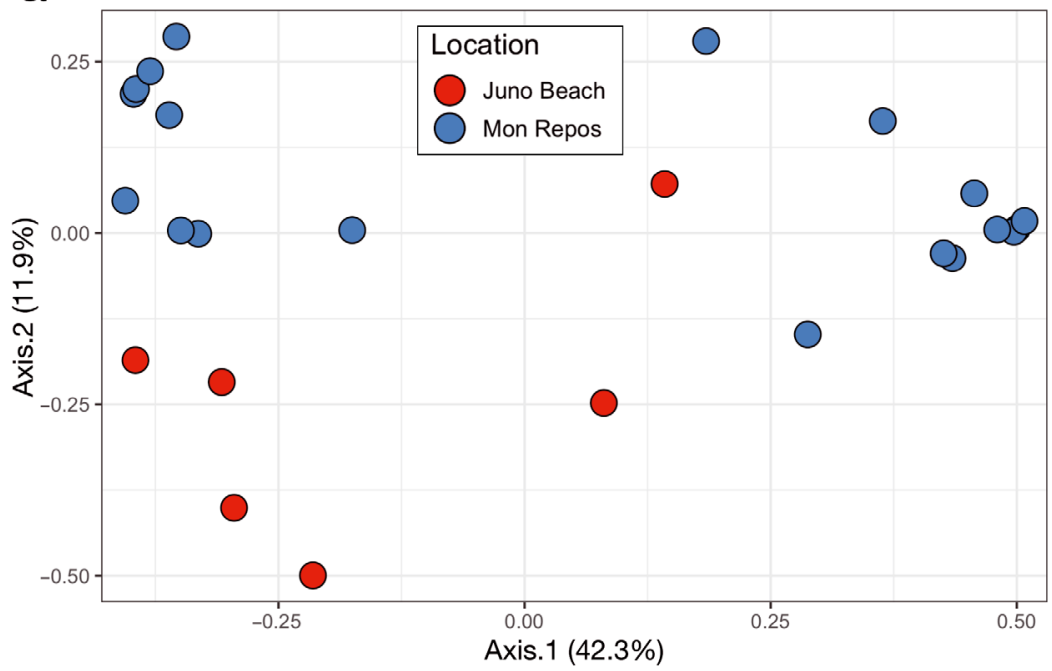

b Flatbacks

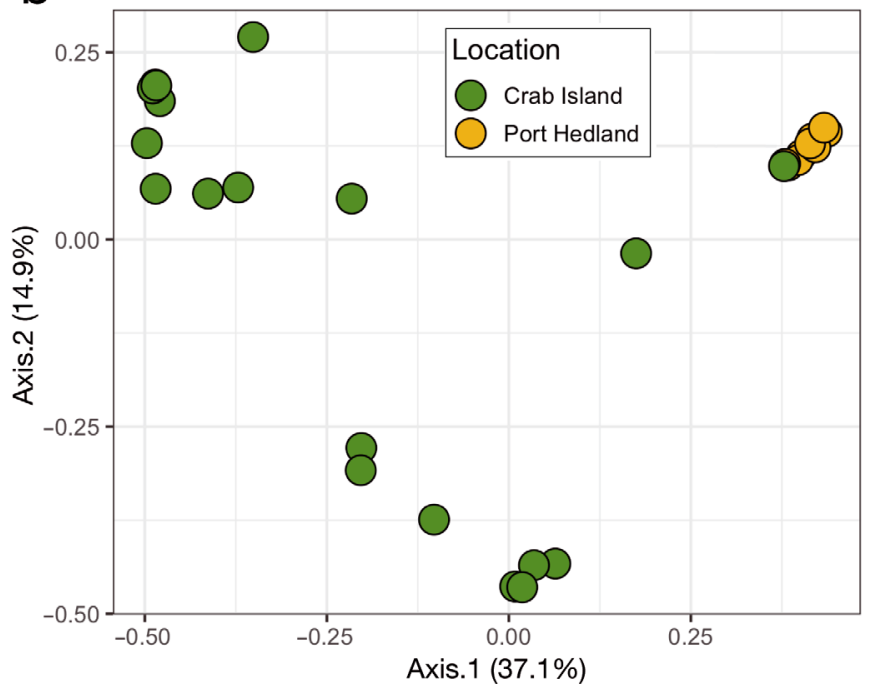

Fig. 3. Principal coordinate analysis plot of Bray-Curtis distances. (a) Comparison of loggerhead turtles from 2 locations: Mon Repos, Australia, and Juno Beach, USA. Observed differences between the populations were significant $(\mathrm{p}=0.03)$. (b) Comparison of flatback turtles from 2 locations: Crab Island, Queensland, and Port Hedland, Western Australia. Each point represents the gut microbiota of an individual turtle. Observed differences between the populations were significant $(p=0.001)$

ties differ significantly among individuals of the same species but which originate from different populations. These differences may be apparent in both composition and diversity. This investigation highlights the importance of interpreting microbiota data in concert with environmental factors and potential genetic differences among host populations. Elucidating the intrinsic and extrinsic causes driving these differences is difficult due to the lack of basic biological data for both individual animals and the different populations of turtles in this investigation. While, broadly speaking, dietary, and migratory information exists for some species and populations of sea turtles, these generalisations should be applied with caution to individuals captured from a nesting beach. For example, nesting loggerheads show a high degree of fidelity to nesting beaches and foraging grounds, but females nesting at the one rookery will have migrated from numerous foraging areas (Limpus 2008b). Female loggerheads tagged at Queensland rookeries have been recorded from feeding areas as far away as Indonesia, Papua New Guinea, Solomon Islands, and New Caledonia, but also from local areas including the Northern Territory, Queensland and New South Wales (Limpus et al. 1992). We were unable to identify the origin of each turtle that was sampled, and therefore it is difficult to determine exactly what factors may be influencing bacterial microbiota community structure in our samples.

In addition to observed differences between sea turtle populations, we also noticed differences between individuals within populations. Such differences have been observed in separate studies looking at loggerhead turtles from the Mediterranean (Abdelrhman et al. 2016, Arizza et al. 2019, Biagi et al. 2019), but no explanations have been given to explain these differences, likely because these investigations were conducted independently. In humans, the establishment and maintenance of the bacterial microbiota are heavily influenced by a range of factors including diet, host genotype, and microbial interactions (Dethlefsen et al. 2006). These factors are further influenced by other random, unpredictable events such as colonisation history. Within an individual, microbes are unevenly distributed, and they have differences in transmissibility (Dethlefsen et al. 2006). This variation is greatly amplified under the paradigm of stochastic niche occupancy, in which microbes must be able to persist and multiply using available resources in the face of fierce competition from existing colonists (Dethlefsen et al. 2006). Such unpredictabil- 

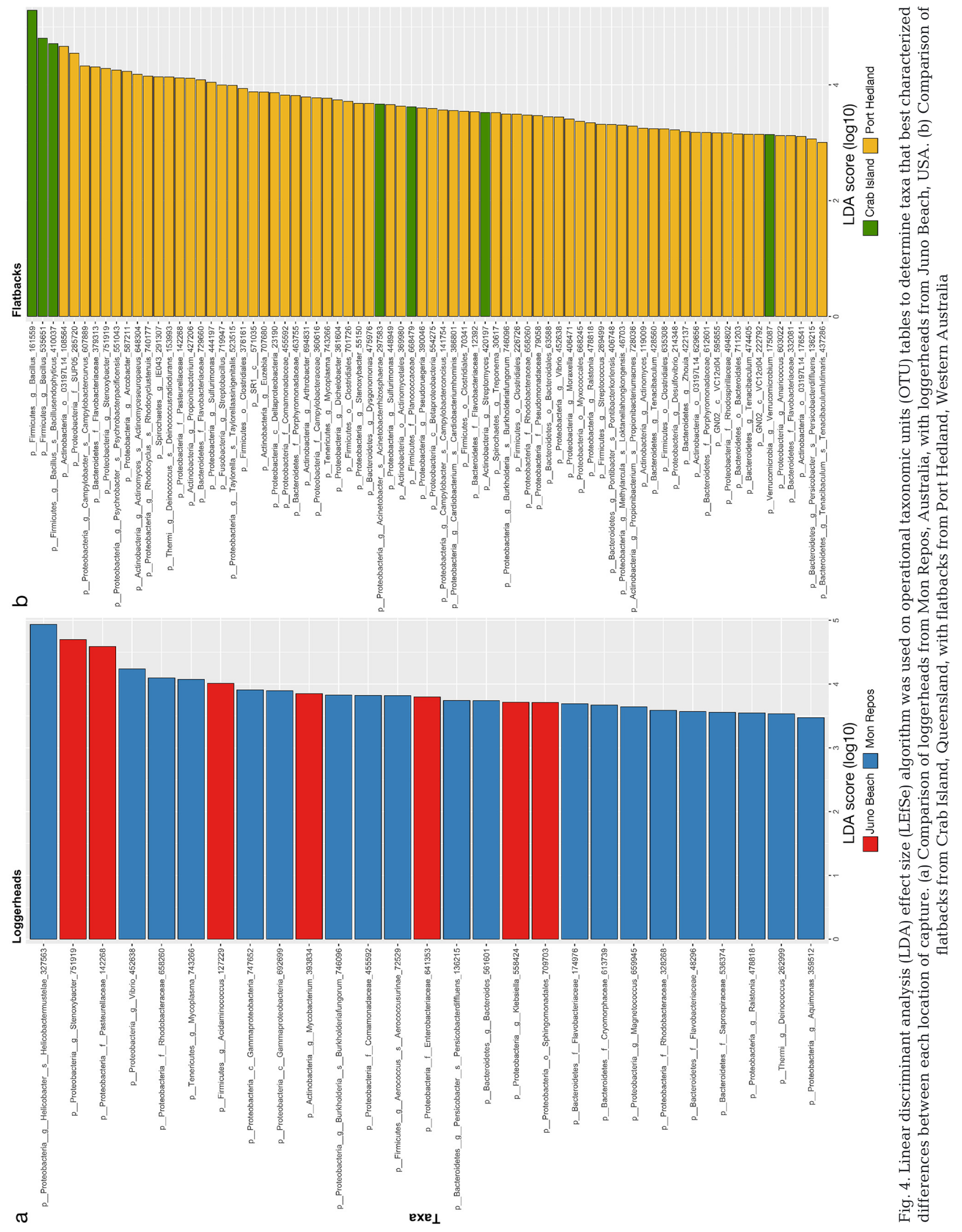
ity accounts for the differences observed in microbiotas between closely related individuals such as inbred mice (Hoy et al. 2015) and human identical twins (Turnbaugh et al. 2010). Therefore, individual variation within a population of animals, such as the turtles in our investigation, is an expected finding.

The role that diet may be playing in determining bacterial microbiota composition in our samples is unknown. Loggerhead turtles are primarily carnivorous (Jones \& Seminoff 2013), feeding on a wide range of prey items with considerable dietary plasticity (Park et al. 2005, Seney \& Musick 2007, Limpus 2008b, Frick et al. 2009). Although there are differences in the species of prey items consumed among loggerhead populations, the taxonomic classes of ingested prey are relatively similar over phylogeographic separations (Jones \& Seminoff 2013). The major differences in dietary preferences come from the proportion of benthic or pelagic fauna in the diet, which is predominately affected by the life stage of the turtle (Jones \& Seminoff 2013). All of the loggerheads in this investigation were adult, and therefore, broad dietary preference is likely to be similar for the 2 populations. In humans, diet markedly affects the microbiota and is principally driven by the volume of fibre consumed (Albenberg \& Wu 2014). It remains to be seen whether or not the observed species-level prey differences across loggerhead populations, rather than dietary variations at genus, family or higher taxonomic levels, selects for specific microbial OTUs in sea turtles.

In addition to food items consumed, food acquisition and digestive strategy can play a role in altering microbial communities in animals. For example, the Burmese python Python molurus is a sit-and-wait predator that consumes enormous, infrequent meals, often punctuated by prolonged periods of starvation (Costello et al. 2010). This feast or famine tactic means that the gastrointestinal tract, including the microbiota, undergoes significant change depending on the presence or absence of food in the gut (Costello et al. 2010). These changes start to become evident between $12 \mathrm{~h}$ to $3 \mathrm{~d}$ after prey ingestion (Costello et al. 2010). Similar patterns of fluctuations in microbial community composition are seen in other vertebrates in response to caloric restriction including humans (Remely et al. 2015), fish (Xia et al. 2014), bears (Sommer et al. 2016), alligators (Keenan et al. 2013), mice (Beli et al. 2018), and penguins (Dewar et al. 2014). Like Burmese pythons, sea turtles may undergo long periods of fasting, particularly during breeding and migration (Hays et al. 2002, Jessop et al. 2004), but how this affects gastrointestinal bacterial community composition is unknown. All animals sampled during this investigation were nesting females, and it is likely that they had been inappetant for an extended period, which may be influencing the bacterial microbiota composition of our populations. It is of particular relevance to study microbiotas of female sea turtles during their egglaying reproductive period because it is the microbiota during this time that is likely to be transferred to their offspring rather than the microbiota during foraging, non-reproductive periods (Scheelings 2019). Given the rapidity with which the bacterial microbiota fluctuates in other vertebrates, it is reasonable to assume that the bacterial microbiota of nesting females is not the same as the bacterial microbiota of foraging animals. Although we were not able to determine how fasting in nesting turtles affects microbial diversity, some authors propose that fasting samples represent the core microbial OTUs, with other OTUs fluctuating in number in response to post-prandial physiological changes (Costello et al. 2010, Keenan et al. 2013). If, as hypothesised, diet has little effect on this core bacterial microbiota, then a possible explanation for differences observed in our loggerhead samples is differences in host genetics. In humans, host genetic variation has been shown to account for microbiota composition from a number of different body sites (Goodrich et al. 2014, Blekhman et al. 2015), and this phenomenon may be a significant contributing factor in the differences observed in our loggerhead populations, given their genetic separation (Bowen \& Karl 2007). In contrast it seems reasonable that genetics is less likely to be contributing to observed differences among flatback populations, given the limited genetic variability in this species compared with loggerheads (Dutton et al. 2002), and so other factors are more important in shaping bacterial microbial communities in flatback populations.

We identified that flatback turtles from Crab Island had much lower microbial diversity than their counterparts from Port Hedland. Such observations in other species have been attributed to habitat degradation and may result in decreased ability of animals to utilise environmental resources (Amato et al. 2013, Barelli et al. 2015, Rosenfeld 2017). We did not attempt to assess habitat quality in this investigation, but Crab Island is a remote, uninhabited island in the Endeavour Strait in the Gulf of Carpentaria with little signs of human impact (authors' pers. obs.). Importantly, it is believed that flatback turtles nesting on Crab Island do not feed in the Gulf of Carpentaria, and so migrate considerable distances from foraging 
grounds for reproduction (Limpus et al. 1993). Thus, in the context of their lives, flatback turtles only spend a relatively short period of time in this area, and therefore any environmental influence is most likely coming from elsewhere. Further work is required to identify the effects that habitat disturbances have on sea turtle bacterial microbiotas, and whether or not they can act as sentinels for oceanic health.

The observed increase in relative abundance of Firmicutes in flatback turtles from Crab Island may possibly be associated with increased adiposity (Bäckhed et al. 2004, Cui et al. 2013). Bacteria from this phylum are able to increase fat metabolism through modulation of the host genes that regulate fat storage (Turnbaugh et al. 2006). Flatback turtles from Western Australia undergo a shorter migration to their natal beaches than Crab Island turtles, as they forage relatively close to their nesting rookeries (Pendoley et al. 2014). This might mean that turtles from Crab Island are inappetant for a longer period of time, and therefore will have a greater reliance on stored body fat to fuel their migration. This physiological phenomenon may preferentially select for Firmicutes as an adaptation to their prolonged fast.

We showed that within sea turtle species, geographic location has a major effect on bacterial microbiota composition. Factors that may explain these observed differences include host genetics, differences in foraging habitat quality and differences in migratory distance (and thus durations of inappetence) between foraging and breeding grounds. The mechanisms by which these factors may influence microbial composition of sea turtle gastrointestinal tracts warrants further investigation. The results of this study highlight the importance of interpreting bacterial microbiota data of wild animals in the context of geography. This study represents the first investigation to explore the effects of population on sea turtle bacterial microbiotas and fills an important knowledge gap in the vertebrate microbiota literature.

Ethics approval. This study was approved by the Biological Sciences Animal Ethics Committee of Monash University (approval 14694). Flatback turtles Natator depressus and loggerhead turtles Caretta caretta were sampled in Queensland under permit WITK17730216 from the Queensland Department of Environment and Heritage Protection and permit G12/35326.1 from the Great Barrier Reef Marine Park Authority. Flatback turtles from Western Australia were sampled under permit 01-000121-1 from the Department of Parks and Wildlife. Loggerhead turtles from the USA were sampled under the permit MTP-18-205A from the Florida Fish and Wildlife Conservation Commission and imported into Australia under permit PWS2018-AU-000738.
Acknowledgements. We thank the following people for their assistance during field work: Ian Bell and Alistair Freeman of the Department of Environment and Heritage Protection, the Apudthama Land and Sea Rangers, Christine Biesgen and the Care for Port Hedland Group, Justin Perrault and the staff of the Loggerhead Marinelife Center, and the Mon Repos Turtle Conservation volunteers.

\section{LITERATURE CITED}

Abdelrhman KFA, Bacci G, Mancusi C, Mengoni A, Serena F, Ugolini A (2016) A first insight into the gut microbiota of the sea turtle Caretta caretta. Front Microbiol 7:1060

Ahasan MS, Waltzek TB, Huerlimann R, Ariel E (2017) Fecal bacterial communities of wild-captured and stranded green turtles (Chelonia mydas) on the Great Barrier Reef. FEMS Microbiol Ecol 93:fix139

Ahasan MS, Waltzek TB, Huerlimann R, Ariel E (2018) Comparative analysis of gut bacterial communities of green turtles (Chelonia mydas) pre-hospitalization and postrehabilitation by high-throughput sequencing of bacterial 16S rRNA gene. Microbiol Res 207:91-99

Albenberg LG, Wu GD (2014) Diet and the intestinal microbiome: associations, functions, and implications for health and disease. Gastroenterology 146:1564-1572

Altschul SF, Madden TL, Schäffer AA, Zhang J, Zhang Z, Miller W, Lipman DJ (1997) Gapped BLAST and PSIBLAST: a new generation of protein database search programs. Nucleic Acids Res 25:3389-3402

Amato KR, Yeoman CJ, Kent A, Righini N and others (2013) Habitat degradation impacts black howler monkey (Alouatta pigra) gastrointestinal microbiomes. ISME J 7: 1344-1353

Arizza V, Vecchioni L, Caracappa S, Sciurba G and others (2019) New insights into the gut microbiome in loggerhead sea turtles Caretta caretta stranded on the Mediterranean coast. PLOS ONE 14:e0220329

Ashelford KE, Chuzhanova NA, Fry JC, Jones AJ, Weightman AJ (2005) At least 1 in 2016 S rRNA sequence records currently held in public repositories is estimated to contain substantial anomalies. Appl Environ Microbiol 71:7724-7736

Bäckhed F, Ding H, Wang T, Hooper LV and others (2004) The gut microbiota as an environmental factor that regulates fat storage. Proc Natl Acad Sci USA 101:15718-15723

* Barelli C, Albanese D, Donati C, Pindo M and others (2015) Habitat fragmentation is associated to gut microbiota diversity of an endangered primate: implications for conservation. Sci Rep 5:14862

* Beli E, Yan Y, Moldovan L, Vieira CP and others (2018) Restructuring of the gut microbiome by intermittent fasting prevents retinopathy and prolongs survival in $d b / d b$ mice. Diabetes 67:1867-1879

* Benson AK, Kelly SA, Legge R, Ma F and others (2010) Individuality in gut microbiota composition is a complex polygenic trait shaped by multiple environmental and host genetic factors. Proc Natl Acad Sci USA 107:18933-18938

* Bestion E, Jacob S, Zinger L, Di Gesu L, Richard M, White J, Cote J (2017) Climate warming reduces gut microbiota diversity in a vertebrate ectotherm. Nat Ecol Evol 1:161

Biagi E, D'amico F, Soverini M, Angelini V and others (2019) Faecal bacterial communities from Mediterranean loggerhead sea turtles (Caretta caretta). Environ Microbiol Rep 11:361-371 
Blekhman R, Goodrich JK, Huang K, Sun Q and others (2015) Host genetic variation impacts microbiome composition across human body sites. Genome Biol 16:191

*Bloodgood JCG, Hernandez SM, Isaiah A, Suchodolski JS and others (2020) The effect of diet on the gastrointestinal microbiome of juvenile rehabilitating green turtles (Chelonia mydas). PLOS ONE 15:e0227060

Bowen BW, Karl SA (2007) Population genetics and phylogeography of sea turtles. Mol Ecol 16:4886-4907

Campos P, Guivernau M, Prenafeta-Boldu FX, Cardona L (2018) Fast acquisition of a polysaccharide fermenting gut microbiome by juvenile green turtles Chelonia mydas after settlement in coastal habitats. Microbiome 6:69

* Caporaso JG, Kuczynski J, Stombaugh J, Bittinger K and others (2010) QIIME allows analysis of high-throughput community sequencing data. Nat Methods 7:335-336

Costello EK, Gordon JI, Secor SM, Knight R (2010) Postprandial remodeling of the gut microbiota in Burmese pythons. ISME J 4:1375-1385

Costello EK, Stagaman K, Dethlefsen L, Bohannan BJ, Relman DA (2012) The application of ecological theory toward an understanding of the human microbiome. Science 336:1255-1262

Coyte KZ, Schluter J, Foster KR (2015) The ecology of the microbiome: networks, competition, and stability. Science 350:663-666

* Cui C, Shen CJ, Jia G, Wang KN (2013) Effect of dietary Bacillus subtilis on proportion of Bacteroidetes and Firmicutes in swine intestine and lipid metabolism. Genet Mol Res 12:1766-1776

David LA, Maurice CF, Carmody RN, Gootenberg DB and others (2014) Diet rapidly and reproducibly alters the human gut microbiome. Nature 505:559-563

DeSantis TZ, Hugenholtz P, Larsen N, Rojas M and others (2006) Greengenes, a chimera-checked 16S rRNA gene database and workbench compatible with ARB. Appl Environ Microbiol 72:5069-5072

Nethlefsen L, Eckburg PB, Bik EM, Relman DA (2006) Assembly of the human intestinal microbiota. Trends Ecol Evol 21:517-523

* Dewar ML, Arnould JP, Krause L, Trathan P, Dann P, Smith SC (2014) Influence of fasting during moult on the faecal microbiota of penguins. PLOS ONE 9:e99996

Duchene S, Frey A, Alfaro-Nunez A, Dutton PH, Thomas PGM, Morin PA (2012) Marine turtle mitogenome phylogenetics and evolution. Mol Phylogenet Evol 65:241-250

Dutton P, Broderick D, Fitzsimmons N 2002. Defining management units: molecular genetics. In: Kinan I (ed) Western Pacific Sea Turtle Cooperative Research \& Management Workshop. Western Pacific Regional Fishery Management Council, Honolulu, HI, 93-101

Edgar RC (2010) Search and clustering orders of magnitude faster than BLAST. Bioinformatics 26:2460-2461

Fadrosh DW, Ma B, Gajer P, Sengamalay N, Ott S, Brotman RM, Ravel J (2014) An improved dual-indexing approach for multiplexed 16S rRNA gene sequencing on the Illumina MiSeq platform. Microbiome 2:6

Fraune S, Bosch TC (2010) Why bacteria matter in animal development and evolution. BioEssays 32:571-580

Frese SA, Parker K, Calvert CC, Mills DA (2015) Diet shapes the gut microbiome of pigs during nursing and weaning. Microbiome 3:28

Frick MG, Williams KL, Bolten AB, Bjorndal KA, Martins HR (2009) Foraging ecology of oceanic-stage loggerhead turtles Caretta caretta. Endang Species Res 9:91-97
Fugate HM, Kapfer JM, McLaughlin RW (2020) Analysis of the microbiota in the fecal material of painted turtles (Chrysemys picta). Curr Microbiol 77:11-14

García-De La Peña C, Garduño-Niño E, Vaca-Paniagua F, Díaz-Velásquez C, Barrows CW, Gomez-Gil B, Valenzuela-Núñez LM (2019) Comparison of the fecal bacterial microbiota composition between wild and captive Bolson tortoises (Gopherus flavomarginatus). Herpetol Conserv Biol 14:587-600

*Goodrich JK, Waters JL, Poole AC, Sutter JL and others (2014) Human genetics shape the gut microbiome. Cell 159:789-799

Green MR, Hughes H, Sambrook J, Maccallum P (2012) Molecular cloning: a laboratory manual. In: Green MR, Sambrook J (eds) Molecular cloning: a laboratory manual, 4th edn. Cold Spring Harbor Laboratory Press, Cold Spring Harbor, NY, p 44-47

*Hays GC, Broderick AC, Glen F, Godley BJ (2002) Change in body mass associated with long-term fasting in a marine reptile: the case of green turtles (Chelonia mydas) at Ascension Island. Can J Zool 80:1299-1302

* Henderson G, Cox F, Ganesh S, Jonker A, Young W (2015) Rumen microbial community composition varies with diet and host, but a core microbiome is found across a wide geographical range. Sci Rep 5:14567

*Holmes IA, Monagan IV Jr, Rabosky DL, Davis Rabosky AR (2019) Metabolically similar cohorts of bacteria exhibit strong cooccurrence patterns with diet items and eukaryotic microbes in lizard guts. Ecol Evol 9:12471-12481

*Hong PY, Wheeler E, Cann IK, Mackie RI (2011) Phylogenetic analysis of the fecal microbial community in herbivorous land and marine iguanas of the Galapagos Islands using $16 \mathrm{~S}$ rRNA-based pyrosequencing. ISME J 5:1461-1470

*Hong PY, Mao Y, Ortiz-Kofoed S, Shah R, Cann I, Mackie RI (2015) Metagenomic-based study of the phylogenetic and functional gene diversity in Galápagos land and marine iguanas. Microb Ecol 69:444-456

*Hoy YE, Bik EM, Lawley TD, Holmes SP, Monack DM, Theriot JA, Relman DA (2015) Variation in taxonomic composition of the fecal microbiota in an inbred mouse strain across individuals and time. PLOS ONE 10:e0142825

Indest KJ, Everman SJ, Lindsay JH, Jung CM, Smith JC, Newell SB (2018) Effects of acute exposures of 2,4,6trinitrotoluene and inorganic lead on the fecal microbiome of the green anole (Anolis carolinensis). PLOS ONE 13:e0208281

Jessop TS, Hamann M, Limpus CJ (2004) Body condition and physiological changes in male green turtles during breeding. Mar Ecol Prog Ser 276:281-288

* Jiang HY, Ma JE, Li J, Zhang XJ and others (2017) Diets alter the gut microbiome of crocodile lizards. Front Microbiol 8:2073

Jones TT, Seminoff JA (2013) Feeding biology: advances from field-based observations, physiological studies, and molecular techniques. In: Wyneken J, Lohmann KJ, Musick JA (eds) The biology of sea turtles. CRC Press, Boca Raton, FL, p 211-248

*Keenan SW, Engel AS, Elsey RM (2013) The alligator gut microbiome and implications for archosaur symbioses. Sci Rep 3:2877

Kittle RP, Mcdermid KJ, Muehlstein L, Balazs GH (2018) Effects of glyphosate herbicide on the gastrointestinal microflora of Hawaiian green turtles (Chelonia mydas) Linnaeus. Mar Pollut Bull 127:170-174 
Kohl KD, Brun A, Magallanes M, Brinkerhoff J and others (2017) Gut microbial ecology of lizards: insights into diversity in the wild, effects of captivity, variation across gut regions and transmission. Mol Ecol 26:1175-1189

Koskella B, Hall LJ, Metcalf CJE (2017) The microbiome beyond the horizon of ecological and evolutionary theory. Nat Ecol Evol 1:1606-1615

Limpus CJ (2008a) Flatback turtle, Natator depressus (Garman). In: Fien L (ed) A biological review of Australian marine turtle species. 5. Queensland Environmental Protection Agency, Queensland, p 1-53

Limpus CJ (2008b) Loggerhead turtle, Caretta caretta (Linnaeus). In: Fien L (ed) A biological review of Australian marine turtles. 1. Queensland Environmental Protection Agency, Queensland, Australia, p 1-67

Limpus CJ, Miller JD, Parmenter CJ, Reimer D, McLachlan N, Webb R (1992) Migration of green (Chelonia mydas) and loggerhead (Caretta caretta) turtles to and from eastern Australian rookeries. Wildl Res 19:347-358

Limpus CJ, Couper PJ, Couper KLD (1993) Crab Island revisited: reassessment of the world's largest flatback turtle rookery after twelve years. Mem Queensl Mus 33: 277-289

Lin M, Zeng C, Li Z, Ma Y, Jia X (2019) Comparative analysis of the composition and function of fecal-gut bacteria in captive juvenile Crocodylus siamensis between healthy and anorexic individuals. MicrobiologyOpen 8: e929

Littleford-Colquhoun BL, Weyrich LS, Kent N, Frere $\mathrm{CH}$ (2019) City life alters the gut microbiome and stable isotope profiling of the eastern water dragon (Intellagama lesueurii). Mol Ecol 28:4592-4607

* Martin MO, Gilman FR, Weiss SL (2010) Sex-specific asymmetry within the cloacal microbiota of the striped plateau lizard, Sceloporus virgatus. Symbiosis 51:97-105

McCord AI, Chapman CA, Weny G, Tumukunde A and others (2014) Fecal microbiomes of non-human primates in Western Uganda reveal species-specific communities largely resistant to habitat perturbation. Am J Primatol 76:347-354

McLaughlin RW, Cochran PA, Dowd SE (2015) Metagenomic analysis of the gut microbiota of the timber rattlesnake, Crotalus horridus. Mol Biol Rep 42:1187-1195

Montoya-Ciriaco N, Gomez-Acata S, Munoz-Arenas LC, Dendooven L, Estrada-Torres A, Diaz De La Vega-Perez AH, Navarro-Noya YE (2020) Dietary effects on gut microbiota of the mesquite lizard Sceloporus grammicus (Wiegmann, 1828) across different altitudes. Microbiome 8:6

Nelson TM, Rogers TL, Carlini AR, Brown MV (2013) Diet and phylogeny shape the gut microbiota of Antarctic seals: a comparison of wild and captive animals. Environ Microbiol 15:1132-1145

Parker DM, Cooke WJ, Balazs GH (2005) Diet of oceanic loggerhead sea turtles (Caretta caretta) in the central North Pacific. Fish Bull 103:142-152

* Pendoley KL, Bell CD, McCracken R, Ball KR and others (2014) Reproductive biology of the flatback turtle Natator depressus in Western Australia. Endang Species Res 23: 115-123

Price JT, Paladino FV, Lamont MM, Witherington BE, Bates ST, Soule T (2017) Characterization of the juvenile green turtle (Chelonia mydas) microbiome throughout an ontogenetic shift from pelagic to neritic habitats. PLOS ONE 12:e0177642
Pritchard PCH (1997) Evolution, phylogeny, and current status. In: Lutz PL, Musick JA (eds) The biology of sea turtles. CRC Press, Boca Raton, FL, p 1-28

* Rafferty AR, Evans RG, Scheelings TF, Reina RD (2013) Limited oxygen availability in utero may constrain the evolution of live birth in reptiles. Am Nat 181:245-253

* Remely M, Hippe B, Geretschlaeger I, Stegmayer S, Hoefinger I, Haslberger A (2015) Increased gut microbiota diversity and abundance of Faecalibacterium prausnitzii and Akkermansia after fasting: a pilot study. Wien Klin Wochenschr 127:394-398

Ren T, Kahrl AF, Wu M, Cox RM (2016) Does adaptive radiation of a host lineage promote ecological diversity of its bacterial communities? A test using gut microbiota of Anolis lizards. Mol Ecol 25:4793-4804

Rosenfeld CS (2017) Gut dysbiosis in animals due to environmental chemical exposures. Front Cell Infect Microbiol 7:396

Scheelings TF (2019) The microbiota of sea turtles. PhD dissertation, Monash University, Clayton

* Scheelings TF, Moore RJ, Van TTH, Klaassen M, Reina RD (2020a) Microbial symbiosis and coevolution of an entire clade of ancient vertebrates: the gut microbiota of sea turtles and its relationship to their phylogenetic history. Amin Microbiome 2:17

* Scheelings TF, Moore RJ, Van TTH, Klaassen M, Reina RD (2020b) No correlation between microbiota composition and blood parameters in nesting flatback turtles (Natator depressus). Sci Rep 10:8333

Seney EE, Musick JA (2007) Historical diet analysis of loggerhead sea turtles (Caretta caretta) in Virginia. Copeia 2007:478-489

* Shreiner AB, Kao JY, Young VB (2015) The gut microbiome in health and in disease. Curr Opin Gastroenterol 31: 69-75

* Sommer F, Stahlman M, Ilkayeva O, Arnemo JM and others (2016) The gut microbiota modulates energy metabolism in the hibernating brown bear Ursus arctos. Cell Rep 14: 1655-1661

Spor A, Koren O, Ley R (2011) Unravelling the effects of the environment and host genotype on the gut microbiome. Nat Rev Microbiol 9:279-290

* Tang W, Zhu G, Shi Q, Yang S and others (2019) Characterizing the microbiota in gastrointestinal tract segments of Rhabdophis subminiatus: dynamic changes and functional predictions. MicrobiologyOpen 8:e789

Trevelline BK, Macleod KJ, Langkilde T, Kohl KD (2019) Gestation alters the gut microbiota of an oviparous lizard. FEMS Microbiol Ecol 95:fiz086

*Turnbaugh PJ, Ley RE, Mahowald MA, Magrini V, Mardis ER, Gordon JI (2006) An obesity-associated gut microbiome with increased capacity for energy harvest. Nature 444:1027-1031

* Turnbaugh PJ, Quince C, Faith JJ, Mchardy AC and others (2010) Organismal, genetic, and transcriptional variation in the deeply sequenced gut microbiomes of identical twins. Proc Natl Acad Sci USA 107:7503-7508

Voreades N, Kozil A, Weir TL (2014) Diet and the development of the human intestinal microbiome. Front Microbiol 5:494

*Willson NL, Van TTH, Lever J, Moore RJ, Stanley D (2019) Characterisation of the intestinal microbiota of commercially farmed saltwater crocodiles, Crocodylus porosus. Appl Microbiol Biotechnol 103:8977-8985

* Xia JH, Lin G, Fu GH, Wan ZY and others (2014) The intes- 
tinal microbiome of fish under starvation. BMC Genomics 15:266

Yuan ML, Dean SH, Longo AV, Rothermel BB, Tuberville TD, Zamudio KR (2015) Kinship, inbreeding and finescale spatial structure influence gut microbiota in a hindgut-fermenting tortoise. Mol Ecol 24:2521-2536

Zakrzewski M, Proietti C, Ellis JJ, Hasan S, Brion MJ, Berger B, Krause L (2017) Calypso: a user-friendly webserver for mining and visualizing microbiome-environment interactions. Bioinformatics 33:782-783

Editorial responsibility: Mark Hamann,

Townsville, Queensland, Australia
Zhang C, Zhang M, Wang S, Han R and others (2010) Interactions between gut microbiota, host genetics and diet relevant to development of metabolic syndromes in mice. ISME J 4:232-241

Z Zhang B, Ren J, Yang D, Liu S, Gong X (2019) Comparative analysis and characterization of the gut microbiota of four farmed snakes from southern China. PeerJ 7:e6658

K Zhao L, Wang G, Siegel P, He C and others (2013) Quantitative genetic background of the host influences gut microbiomes in chickens. Sci Rep 3:1163

Submitted: September 6, 2019; Accepted: May 8, 2020

Proofs received from author(s): June 27, 2020 